\title{
Considerações sobre o Design de jogos e brinquedos pedagógicos para o ensino da matemática no Ensino Fundamental
}

Eliany Maria de Medeiros Silva;

Wellington Gomes de Medeiros

resumo:

O presente trabalho descreve fundamentação teórica de uma pesquisa em andamento sobre o design de jogos e brinquedos pedagógicos e sua utilização como instrumentos que auxiliam o ensino da matemática com o objetivo de tornar as aulas mais dinâmicas, prazerosas e eficientes. Para tanto, o estudo investiga a relação entre a composição dos atributos físicos dos jogos e brinquedos pedagógicos e o processo de ensino-aprendizagem. $\mathrm{O}$ trabalho discute a importância dos atributos do Design com finalidades didáticas, ou seja, busca compreender como os elementos físicos desses produtos se tornam características importantes no processo de ensino. Este artigo apresenta uma breve análise sobre o design de jogos e brinquedos pedagógicos e a relevância de utilizar esse tipo de recurso para o ensino da matemática, considerando que vem se tornando cada vez mais presente no campo educacional, como forma de tornar as aulas da disciplina mais atrativas e motivadores, possibilitando uma maior interação, envolvimento e participação dos alunos.

palavras-chave:

Jogos e brinquedos pedagógicos; Design; Ensino; Matemática. 


\section{Introdução}

Pensar sobre jogos e brinquedos, no primeiro momento, parece ser uma tarefa simples, afinal estes objetos estão presentes na vida de toda e qualquer criança, desde os tempos mais antigos. Porém, quando analisamos esses artefatos de forma mais aprofundada podemos perceber que alguns jogos e brinquedos favorecem o ensino de atividades educacionais, coordenações ou algum tipo de conteúdo para as crianças.

Neste sentindo, os jogos e brinquedos pedagógicos estão presentes no contexto educacional, como uma ferramenta utilizada para auxiliar o processo de ensino-aprendizagem. Nestes casos, os jogos e brinquedos assumem mais do que apenas o papel de entretenimento, eles assumem um papel de proporcionar ensinamentos, assim como, através deles, as crianças conseguem desenvolver características como a criatividade, a socialização, desenvolvimento cognitivo, dentre outros fatores.

Deste modo, é necessário que haja uma melhor compreensão de como esses jogos e brinquedos podem auxiliar na transmissão de conhecimento, e como o Design e a composição dos atributos estão relacionados aos conteúdos didáticos. A criação e construção dos jogos e brinquedos pedagógicos está diretamente relacionada com o processo de ensino e aprendizagem das crianças, de forma a auxiliar o professor em sala de aula. Nesse sentido, esse estudo investiga a utilização deste material didáticopedagógico pelos professores no processo de ensino-aprendizagem da disciplina da matemática no ensino fundamental.

Neste contexto, este artigo tem como objetivo investigar o uso de jogos e brinquedos pedagógicos como uma ferramenta que auxilia o processo de ensino-aprendizagem na disciplina da matemática, além de averiguar, as possibilidades dentro do campo do Design, quando aliada a Educação, de modo que seja possível observar o desenvolvimento dos projetos de jogos e brinquedos pedagógicos, direcionados para a disciplina da matemática. Para isso, como procedimento metodológico, foi conduzida uma pesquisa exploratória de cunho bibliográfico em publicações da área acerca do design dos jogos e brinquedos pedagógicos e sobre sua aplicação no ensino da matemática.

\section{Jogos e brinquedos pedagógicos no ensino da matemática}

A sociedade da informação, como pode ser denominada a atual sociedade, exige uma nova maneira de pensar, assim como, sugere novos tipos de condutas sociais. Sendo assim, nada mais justo, do que começar essas novas formas de conhecimento e transformações, a partir da Educação. Com o apoio das novas ferramentas tecnológicas, as escolas se preparam cada vez mais para formar com mais eficiência os alunos e estudantes para os novos desafios do futuro.

O Anuário Brasileiro da Educação Básica (2019), apresenta dados recentes sobre a atual situação do ensino no Brasil, evidenciando a evolução da educação no país. Ao longo das várias etapas escolares que os estudantes cursam, o primeiro momento de avaliação ocorre por meio da Avaliação Nacional da Alfabetização (ANA), que mede o grau de conhecimentos específicos dos alunos em leitura, escrita e matemática. De acordo com ele, os últimos resultados divulgados sobre provas realizadas entre 2014 e 2016, relata que as dificuldades encontradas na aprendizagem no Brasil se iniciam desde os primeiros anos de escolaridade.

De acordo com o Anuário Brasileiro da Educação Básica (2019), analisando os anos iniciais do ensino fundamental que vai do $1^{\circ}$ ao $5^{\circ}$ ano, é no $3^{\circ}$ ano que acontece uma redução na taxa de aprovação, tendo apenas $89,5 \%$ de alunos aprovados. Já do $6^{\circ}$ ao $9^{\circ}$ ano do ensino fundamental, o menor índice de aprovação acontece no $6^{\circ}$ ano com $84,5 \%$ e a partir deste, passa-se a ter pequenos aumentos até o $9^{\circ}$ ano, finalizando ainda em apenas $89,6 \%$ de alunos aprovados. 
Tabela 1 - Taxas de aprovação, reprovação e abandono no ensino fundamental

\begin{tabular}{|c|c|c|c|}
\hline EF & Aprovação & Reprovação & Abandono \\
\hline $1^{\circ}$ ano & 98,0 & 1,2 & 0,8 \\
\hline $2^{\circ}$ ano & 97,2 & 2,2 & 0,6 \\
\hline $3^{\circ}$ ano & 89,5 & 9,7 & 0,8 \\
\hline $4^{\circ}$ ano & 92,8 & 6,3 & 0,9 \\
\hline $5^{\circ}$ ano & 93,1 & 5,9 & 1,0 \\
\hline $6^{\circ}$ ano & 84,5 & 12,7 & 2,8 \\
\hline $7^{\circ}$ ano & 86,5 & 10,9 & 2,6 \\
\hline $8^{\circ}$ ano & 88,7 & 8,8 & 2,5 \\
\hline $9^{\circ}$ ano & 89,6 & 7,5 & 2,9 \\
\hline
\end{tabular}

Fonte: $\mathrm{MEC} /$ Inep/DEED/Indicadores Educacionais.

Fonte: Anuário Brasileiro da Educação Básica (2019)

No Brasil, o ensino da matemática se caracteriza pelo uso de métodos tradicionais, nos quais o aluno recebe a informação e realiza atividades e exercícios na tentativa de memorizar os conteúdos. Deste modo, os alunos assimilam os assuntos da disciplina sem conseguir manter uma conexão direta entre os conteúdos ensinados e o seu dia-a-dia, o que reduz um conjunto de significados e ainda compromete o aprendizado. Este método de ensino também dificulta a realização de outras atividades pelos alunos, como o pensamento estratégico e a resolução de problemas.

Os Parâmetros Curriculares Nacionais - PCN (BRASIL, 1997) indicam o surgimento de propostas pedagógicas inovadoras, de maneira que possibilitem contribuir para uma modificação no ensino da matemática para que o corpo docente consiga beneficiar o ensino e a aprendizagem dessa disciplina.

No contexto atual do Brasil, verifica-se o descontentamento dos alunos com a disciplina da matemática, o alto nível de reprovação e as grandes dificuldades encontradas pelos alunos em assimilar os conteúdos dessa disciplina. Esses fatores apontam para a grande necessidade dos docentes de tentar melhorar a qualidade do ensino, ou seja, os professores da matemática estão procurando apresentar novas metodologias e estratégias de ensino (BRASIL, 1997, p. 12).

Destacamos assim, a importante influência do professor na discussão e constituição de novos paradigmas metodológicos de ensino, já que ele é um contribuinte significante na formação dos alunos, pois é o principal responsável pela transmissão dos conteúdos, ou seja, através dele o conhecimento da disciplina chega até os alunos (SILVA, 2013).

Para o ensino da matemática, de acordo com o PISA - Programa Internacional de Avaliação de Estudantes (2015, apud ANUÁRIO BRASILEIRO DA EDUCAÇÃO BÁSICA, 2019), menos de um terço dos estudantes brasileiros conseguem alcançar um nível de proficiência adequado em matemática. Além do mais, os parâmetros da Organização para a Cooperação e o Desenvolvimento Econômico (OCDE), mostram uma alta porcentagem de estudantes que tiveram baixo desempenho na avaliação. 


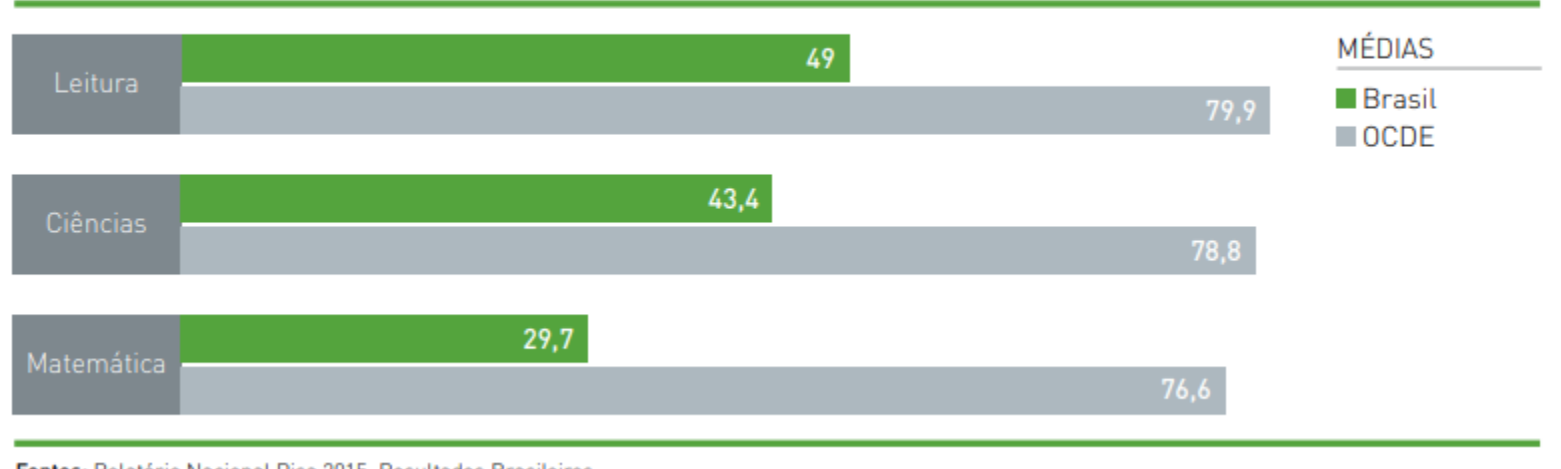

Fontes: Relatório Nacional Pisa 2015. Resultados Brasileiros.

Gráfico 1 - Porcentagem de estudantes acima do nível 2 no Brasil Fonte: Anuário Brasileiro da Educação Básica (2019)

De acordo com Santana, Borges Neto e Rocha (2004) as aulas na disciplina da matemática são explanadas de maneira habitual com apresentação dos conteúdos, sem uma relação mais próxima com os alunos. Os docentes se habituaram a utilizar o método pedagógico de ensino similar àquele ao qual lhes foi ensinado, gerando um dos maiores problemas relacionado ao ensino da matemática. Os conteúdos matemáticos, são derivados de um processo que envolve imaginação, estratégias, críticas, acertos e erros, porém, tem sido explanado de forma generalizada, descontextualizada e atemporal, o que gera um resultado insatisfatório para a disciplina (BRASIL, 1997, p. 20).

Quanto à utilização de jogos e brinquedos pedagógicos para o ensino da matemática, observase que sua implementação se deve à ampla necessidade dos professores de utilizarem material didático mais eficaz, além de buscar um método de ensino que favoreça a motivação dos alunos. Esse método também possibilita a exploração da concentração e do raciocínio lógico, de modo que o professor passou a ser mais do que um transmissor de conhecimentos, mas um mediador e incentivador da aprendizagem (GODOY, MENEGAZZI, 2014).

Entre os séculos XVII e XVIII, conceitos relacionados à infância sofreram mudanças, quando a criança adquiriu maior relevância nas diversas áreas de estudo. Nesse contexto, surgiu a necessidade de analisar a importância que os jogos e brinquedos apresentariam para o processo de desenvolvimentos das crianças (MEFANO, 2005).

Entre os grandes pesquisadores, destacou-se Frobel por ser um dos pioneiros em evidenciar a importância dos jogos e brinquedos para as conexões humanas. Ele também elaborou uma série de jogos para que fossem empregados como apoio pedagógico no então denominado jardim de infância, estágio preliminar de estudo que deve estimular a criança a resolver desafios a partir de situações criadas que provoquem desequilíbrios cognitivos e consequentes busca por soluções. Até então, entende-se que não existe ensino sem que aconteça o processo de aprendizagem. De acordo com Borges (1994), não é coerente que aconteça a formação de indivíduos que apenas reproduzam modelos. A criança tem o direito de cometer equívocos e a partir disso, conseguir aprender com seus erros e acertos de forma que essas tentativas vão contribuir para a sua construção intelectual. Diante disso, compete ao professor, ajudar a criança nesse processo construtivista de modo que ela consiga resolver problemas e solucionar desafios, sozinhos (MARCATO, 2009, p.56).

Tanto na educação infantil quanto nos anos iniciais do ensino fundamental, a matemática se destaca como uma disciplina intensamente presente no dia-a-dia dos alunos. Desta forma, procura-se a imersão de atividades lúdicas no ensino, ressaltando cada vez mais uma melhor aprendizagem para os alunos. Grando (2004), afirma que "desde os primeiros anos de vida, (a criança) brinca, joga e desempenha atividades lúdicas. $\mathrm{Na}$ verdade, o mundo da criança é uma realidade de jogo." (GRANDO, 2004, p. 61).

Segundo Silva (2015), uma das formas mais eficientes para sanar as dificuldades na disciplina da matemática é por meio de uma metodologia didática que está relacionada com o lúdico, onde se torne possível que os alunos avaliem e observem de maneira crítica a resolução de problemas. De acordo com Marcato (2009), o processo de ensino-aprendizagem é evidenciado através da realização 
de atividades lúdicas, de forma que através dos materiais lúdicos, é possível observar o processo de aprendizagem bem definido, como é o caso dos jogos e brinquedos pedagógicos (MARCATO, 2009, p.56).

De acordo com Lira e Rubio (2014) as crianças conseguem aprender de forma mais satisfatória brincando e dentro da disciplina da matemática, vários são os conteúdos que podem ser ministrados por meio dos jogos, brinquedos e brincadeiras. Estes materiais podem ter objetivos didáticospedagógicos, proporcionando um melhor desenvolvimento dos estudantes, por meio do desenvolvimento cognitivo, motor, afetivo, psicológico e social, além disso, consegue estimular a relação da criança consigo mesmo, com seus colegas e com o mundo ao seu redor (LIRA, RUBIO, 2014, p.20).

Kishimoto (2005) afirma que os jogos e brinquedos pedagógicos são importantes ferramenta para auxiliar no processo de ensino-aprendizagem, além de colaborar para o desenvolvimento infantil. Por meio dos jogos e brinquedos, a criança consegue aprender de maneira mais espontânea e livre com processos interativos, cooperando para o desenvolvimento seja de processos afetivos, sociais e cognitivos.

A utilização de jogos e brinquedos como instrumentos no ensino da matemática é algo que vem acontecendo há muito tempo ao longo da história. Algumas tipologias de jogos começaram a surgir envolvendo casos problemáticos com números e formas geométricas, que forneceram a possibilidade de realização de estudos mais aprofundados, acarretando no desenvolvimento do próprio jogo e no descobrimento de características matemáticas inovadoras (MOREIRA E OLIVEIRA, 2004, p.70).

Brisch e Sehn (2017) também afirmam que é possível utilizar os jogos e brinquedos pedagógicos a favor das transformações no ensino das aulas de matemática, de maneira que essa metodologia permita aos alunos um caminho para aprender conteúdos através do uso de um material concreto, além de auxiliar na construção de seus conhecimentos. Deste modo, a maneira como os professores trabalham os conteúdos matemáticos de forma mais agradável e encantadora no processo de ensino-aprendizagem, fornece a realização da prática do brincar pedagógico, fundamentada pelo ato da utilização de atividades que envolvam a ludicidade e que tenham o objetivo de desenvolver nos alunos experiências mais espontâneas e dinâmicas, conseguindo assim, uma aprendizagem mais satisfatória (SILVA, 2015, p.17).

Nesse contexto, é importante ressaltar ainda, que para que os jogos e brinquedos sejam utilizados de forma mais eficaz no âmbito educacional, é interessante que seja aplicado o lúdico no processo de ensino e aprendizagem, através da interação desses produtos por meio dos educadores (BICALHO, OLIVEIRA, AZEVEDO, 2019).

Kishimoto (2005), afirma que o uso de jogos e brinquedos pedagógicos é importante no sentindo que promove as condições de aprendizagem dos alunos auxiliando o desenvolvimento da criança em diversos aspectos.

De acordo com Oliveira (2010), vários são os tipos de jogos e brinquedos que podem auxiliar no desenvolvimento visual, auditivo, tátil e motor da criança. $\mathrm{O}$ autor cita jogos de memória, jogos de encaixes, brinquedos de montar, cubos, estruturas com pinos coloridos e várias outras tipologias de jogos e brinquedos que possuem qualidades que favorecem o desenvolvimento da criança. (OLIVEIRA, 2010, p.48-49).

Segundo Bessa e Costa (2017), o resultado satisfatório da utilização dos jogos e brinquedos pedagógicos para o ensino da matemática está relacionado também ao fato de que, segundo as teorias de Piaget, o desenvolvimento da inteligência deriva de uma execução progressiva de ações, ou seja, as ações vindo antes da relação com o pensamento, por isso, a utilização dos jogos como prática são mais eficientes antes de explicar as teorias.

A ampla utilização dessa metodologia para auxiliar o ensino da matemática deve-se ao extenso suporte em vários aspectos que oferece para o ensino-aprendizagem. Além disso, ressalta-se a extrema importância dos professores nesse cenário, já que eles são os mediadores da relação dos alunos com os jogos e brinquedos. Os professores também são responsáveis por analisar e escolher os objetos que serão utilizados em sala de aula, de modo a melhorar seu método de ensino. A disciplina da matemática está repleta de ações onde se identificam características individuais dos problemas no ensino-aprendizagem. Nesse contexto, vários congressos sobre educação matemática patrocinados 
pela Unesco também contribuíram para um aspecto desarticulado dos problemas no ensino da matemática (KISHIMOTO, 2005, p.74, 84).

Os professores experimentam a utilização de jogos e materiais pedagógicos, na elaboração da atividade de ensino, ao avaliar nos planos afetivos e cognitivos, os objetivos, a capacidade do aluno, os elementos culturais e os instrumentos de forma material e psicológica apropriadas para colocar o pensamento da criança em ação. Desta forma, verifica-se a importância da atividade guia de aprendizagem (Moura, 1992). Sendo assim, o professor também se torna, um importante elemento na organização da ação pedagógica (KISHIMOTO, 2005, p.84).

Considerando o que foi exposto acima, observa-se que tem se tornado um desafio diário pra os professores da matemática encontrar uma maneira na qual os alunos aprendam os conteúdos de forma que também se identifiquem com a disciplina, tornando possível a resolução de problemas e a compreensão dos conteúdos. Deste modo, os professores buscam encontrar novas metodologias de ensino, onde possam utilizar uma técnica em sala de aula de forma mais dinâmica, significativa e satisfatória. $\mathrm{O}$ uso de jogos e brinquedos pedagógicos surgem como uma maneira de conseguir aplicar os problemas matemáticos, e tem sido bastante utilizado nas aulas dessa disciplina por ser uma ferramenta que transmite o conteúdo de forma mais ágil, prática e contextualizada. Por isso, pode-se considerar o uso dos jogos e brinquedos para o ensino da matemática como tática de ensino eficaz e como uma tendência existente no campo educacional da disciplina.

\section{A importância do Design de jogos e brinquedos pedagógicos}

Toda criança tende a perceber melhor as formas e dimensões dos objetos na fase projetiva da sua infância, quando começa a perceber fatores como: ângulos, formas e distâncias. É nesta fase que conseguimos observar a importância da compreensão física dos objetos, ou seja, do design de jogos e brinquedos (LORENZATO, 2006 apud MARCATO, 2009).

De acordo com Mefano (2005), ao elaborar ou projetar objetos, o designer atribui aos artefatos determinados valores e significados, de forma que os objetos não se tornem produtos avulsos dentro do seu próprio conjunto de uso. Já para Coelho (2008), seja qual for a área de atuação do design, é necessário fazer uma constituição a partir de vários significados, sejam eles sobre aspectos de produção, de uso, de impacto ao meio ambiente, dentre outras possibilidades (COELHO, 2008, p.219).

Segundo Landim (2013), um projeto de design, tem por objetivo atender as necessidades e os desejos dos usuários, levando em consideração aspectos emocionais, ergonômicos e funcionais que podem atribuir sobrevida a um produto, contribuindo para o bem estar de seus usuários (LANDIM et al., 2013 apud CRUZ, 2017, p.28).

O Design de jogos e brinquedos pedagógicos ainda é uma área pouco estudada no Brasil. Os estudos mais desenvolvidos sobre esse tema são originários dos Estados Unidos e da Europa. Além disso, os jogos e brinquedos só adquiriram relevância na infância em meados do século XIX, quando surgiu a necessidades de produtos que apresentassem características próprias considerando suas especificidades e atitudes diferenciadas no desenvolvimento dos produtos. Para o designer voltado para o desenvolvimento de jogos e brinquedos, se faz necessário a obtenção de algumas informações, como: a interpretação das necessidades, curiosidades e interesses daquela criança ou usuário. A elaboração desse tipo de produto envolve imaginação, inteligência, motivação e muita persistência (CALEGARI; SILVA, 2017; MEFANO, 2005, p.86).

Segundo Mefano (2005), no processo de criação de jogos e brinquedos, o designer busca contemplar várias atividades em um só produto. É necessário pensar o produto como um todo segundo sua complexidade, englobando características de marketing e de engenharia, de forma que todos esses itens estejam conectados em um só artefato. Além disso, ainda é necessário que o designer seja criativo no desenvolvimento de seus produtos de forma que sejam inovadores e atrativos para as crianças.

Nesse contexto, observa-se que na infância e no desenvolvimento de toda e qualquer criança pode existir a incrementarão de jogos e brinquedos pedagógicos. O ato de brincar é apresentado como uma ferramenta de fundamental importância no desenvolvimento de uma criança, já que esse ato pode estimular várias capacidades motoras, sociais e emocionais. Na brincadeira, as crianças conseguem exercer atividades lúdicas e educativas que podem ser trabalhadas em sala de aula (GUTHEIL et al., 2015). Sendo assim, os jogos e brinquedos adquirem um papel de entretenimento, divertimento além 
de proporcionar e fornecer conhecimentos para as crianças. Além disso, é possível desenvolver várias outras habilidades, como: a criatividade, o raciocínio, a socialização, a percepção e o desenvolvimento cognitivo.

De acordo com Barata (2018) os jogos e brinquedos são elaborados com o desígnio de auxiliar as crianças em vários aspectos, tanto sociais como emocionais. Dentre eles, podemos destacar: a concentração, a memória, a imaginação e a percepção visual. Esses objetos têm o intuito de transmitir conhecimento para a criança, de forma que ao mesmo tempo, ela consiga brincar e aprender. Como exemplo disto, podemos destacar os jogos e brinquedos coloridos, os que apresentam diferentes formas, os que emitem sons, dentre outros.

Barata (2018) também destaca algumas propriedades dos jogos e brinquedos como de extrema importância para as crianças. "As cores vivas, as texturas fofas, os materiais suaves, as músicas alegres, as formas arredondadas, são características de brinquedos com grande apelo e atração por parte das crianças." (BARATA, 2018, p.62).

Por outro lado, Kishimoto (2005) enriquece o debate sobre o uso de jogos e brinquedos no âmbito educacional ao elaborar uma análise por meio de uma extensa revisão bibliográfica sobre o assunto, ressaltando como esse material pode auxiliar o ensino da matemática, levando professores e educadores a usarem diversos tipos de material como: geoplano, material dourado, réguas de cuisenaire, blocos lógicos, ábacos, cartaz de prega, sólidos geométricos, quadros de frações equivalentes, jogos de encaixe, quebra-cabeças e muitos outros (KISHIMOTO, 2005, p.83).

Deste modo, destaca-se a relevância da utilização dos jogos e brinquedos, como material lúdico e didático, sendo bastante empregados especialmente para as disciplinas que os alunos apresentam um maior grau de dificuldade. Nesse cenário, Calegari e Silva (2017), ressaltam a grande importância da composição física dos jogos e brinquedos, sendo que, cada objeto é projetado e qualificado de acordo com as necessidades e finalidades aos quais precisa atingir.

Os jogos e brinquedos são potencializadores do conhecimento, e essa atribuição também está relacionada às características físicas que compõem cada produto. Os atributos como a forma, o material e a cor, são propriedades que apresentam grande importância para a criança, já que estão diretamente ligados à aparência do produto. A função estética pode, portanto, ser mais decisiva que a função prática no processo de comunicação entre o produto e a criança. A aparência estética estabelece uma comunicação que contém uma série de informações que são transmitidas para os usuários, devendo ser parte do processo criativo do designer a consulta aos futuros consumidores do produto na criação de brinquedos e jogos (BARATA, 2018, p. 55).

De acordo com Marcato (2009), é interessante ressaltar que o design é uma comunicação visual, ou seja, é uma forma de manter um diálogo diretamente com os usuários, sendo assim, o visual do produto se torna uma linguagem. Nesse contexto, o design estabelece uma linha tênue com a forma do produto já que este elemento está relacionado ao visual dos objetos e permitem a apresentação do artefato. É importante lembrar, que é sempre necessário ter cuidado ao planejar e projetar um objeto com finalidade pedagógica, como os jogos e brinquedos, já que a assimilação de conteúdo pode estar diretamente relacionada a sua representação visual.

Deste modo, observa-se que ao trabalhar com este tipo de produto, deve-se obter muito capricho durante seu processo de design, analisando formas para que os jogos e brinquedos se tornem mais interessantes e atraentes, de modo a responder melhor as necessidades físicas, estéticas e intelectuais das crianças. Nesse contexto, o designer se fixa também como uma agente educacional, com a finalidade de atender as necessidades e ainda implantar melhorias no projeto deste tipo de produto, já que, o conceito inserido nesse produto irá se tornar um elemento educativo na medida que será utilizado como uma ferramenta didático pedagógica. (MARCATO, 2009).

O design faz parte da sociedade com o dever de pensar e criar produtos. Neste caso, ferramentas para auxiliar a educação, e favorecer a evolução dos alunos desde a área de conhecimentos até as próprias relações sociais, estimulando cada vez mais a vivência da criança com o seu ambiente físico escolar. Sendo assim, é possível verificar que a eficácia do produto está relacionada a alguns fatores tangíveis, de modo que sua composição deve derivar uma combinação eficiente. Isso também depende dos designers que projetam estes produtos, ou seja, da intenção ao qual será dada para aquele artefato, visando oferecer a sociedade um produto de qualidade. 


\section{Atributos do Produto de Design}

O Design é uma atividade projetual que torna possível que a cada dia, surjam novos produtos planejados de forma a satisfazer as necessidades dos seus usuários. Consiste em determinar as características físicas dos objetos que são produzidos, de forma que possibilite a invocação e o desenvolvimento tecnológicos de novos produtos (HESKETT, 2008, p.13). Na atualidade, a concepção de produtos com tecnologias inovadoras, tem se tornado cada dia mais importante demanda para os designers. Este fato torna imperativo que os profissionais da área tenham ideias inovadoras e concepções apropriadas.

O desenvolvimento do objeto implica na pesquisa criteriosa por parte dos designers acerca dos atributos que formatarão os produtos considerando não apenas suas características tangíveis mas também seu potencial intangível, como sua dimensão simbólica. Estes atributos, consistem nas características físicas, ou seja, os elementos da composição formal do produto (SEHN, 2014).

Manzini (1993), afirma que os usuários conseguem compreender as características físicas dos produtos, como a cor, a textura e a forma através do efeito sensorial. Por sua vez, Dondis (2003), discute sobre a seriedade da leitura visual dos produtos, argumentando que é por meio do alfabetismo visual que o usuário pode atingir a plena compreensão das funções de um produto. De acordo com o autor, é importante entender os elementos individuais dos produtos e o poder de expressão que cada um deles tem, como: a textura, a forma, a cor, dentre outros, formando o que afirma ser a sintaxe visual do produto. Ainda de acordo com Dondis (2003), existem elementos básicos que podem ser estudados e compreendidos por estudiosos da comunicação visual e que podem ser utilizados para a elaboração de mensagens visuais mais claras. É através do conhecimento destes fatores, que se pode ter uma compreensão melhor das mensagens visuais. (DONDIS, 2003, p.18).

Para Dondis (2003), o "alfabetismo visual significa uma inteligência visual", ou seja, a alfabetização visual se torna o elemento mais importante para que se tenha uma comunicação visual. A maneira de entender os elementos visuais, as composições e as relações que ocorrem nos objetos dependem do entendimento do design.

Outros autores também relatam a importância de entender as características tangíveis do design. Lobach (2001) atribui ao designer a competência de criar as funções estéticas dos produtos, que surgem de acordo com as necessidades dos usuários, sendo a estética do objeto a dimensão na qual se instauram suas características visuais. $\mathrm{O}$ autor também afirma que é importante projetar as possíveis relações das pessoas com os objetos (LÖBACH, p. 159, 2001), mesmo considerando a imprevisibilidade natural da interação.

Para Lobach (2001), o conceito principal sobre a estética do objeto está relacionado a forma, tanto de um objeto estético quanto de um produto industrial. A forma do produto resulta do somatório de elementos da configuração e das relações recíprocas que se situam entres todos os elementos. (LÖBACH, p. 159, 2001). Além disso, para o autor, os aspectos fundamentais de relação entre os usuários e os produtos, está relacionado também a função do artefato, as quais se tornam perceptíveis no processo de uso e permitem a satisfação das necessidades dos usuários. (LÖBACH, 2001, p. 54).

Ainda de acordo com Lobach (2001) é importante ressaltar que só é possível elaborar o projeto de um produto novo que atenda devidamente os valores do Design, e que ao mesmo tempo consiga responder às necessidades dos consumidores, quando se tem conhecimento e compreensão das características daquele produto. $\mathrm{O}$ autor faz menção a determinados elementos da estética do objeto, como: forma, material, superfície, cor, ordem e complexidade.

Segundo Silveira (2018), as formas e os elementos visuais que fazem a composição do design, são capazes de manter uma comunicação, que pode ou não ser eficaz, dependendo do objetivo do designer quanto gerador da forma, na hora de planejar o produto, organizando suas funções e planejando as interfaces do objeto. (SILVEIRA, 2018, p.41).

Outros autores também fazem referência aos elementos físicos dos objetos, dentre eles, destaca-se Gomes Filho (2008), que faz alusão às características que tornam possível um sistema de leitura visual a partir da teoria da Gestalt. Por meio de estudos e pesquisas experimentais, os gestaltistas estabeleceram suas teorias que vai sugerir uma resposta ao porquê de umas formas agradarem mais e outras não. Deste modo, a partir das leis de Gestalt foi possível criar uma espécie de "abecê da leitura visual", de modo que promove facilidade na compreensão da forma do objeto. (GOMES FILHO, 2008, p. 18). 
De acordo com Peter e Olson (1996) os atributos do produto são o principal elemento que influência o consumidor na sua decisão, levando em consideração as funções e seus próprios valores, crenças e experiências. (PETER, OLSON, 1996 apud SEHN, 2014).

Dentro desse contexto pode-se verificar que a composição física dos objetos, relacionada diretamente aos atributos dos produtos, tem grande importância no seu contexto como um todo. Para Barata (2018), a função estética dos produtos, tem uma importância fundamental para a composição dos valores estéticos dos artefatos, que são gerados a partir das funções de cada produto. Ainda de acordo com o autor, atributos como a cor, o material, a dimensão e a superfície são componentes básicos de extrema importância que contribuem para a identificação rápida do produto, ou seja, cada um deste elementos transmitem uma quantidade de informações para os usuários, com um valor de influência consideravelmente sólido.

Segundo Barata (2018), para o campo dos jogos e brinquedos pedagógicos podemos observar a importância dos atributos, devido ao fato que normalmente as características dos produtos já tem a função de transmitir informações para os usuários e em especial este tipo de produto, que vai ter uma relação direta com a criança e ainda vai influenciar na sua aprendizagem, já que são produtos utilizados no processo de ensino. Como exemplo, temos a forma do produto, que se constitui no conjunto de configuração externa do objeto e se trata do primeiro contato e percepção que a criança tem com o artefato.

A textura e os materiais também são elementos importantes no processo de composição de um objeto, no caso dos jogos e brinquedos, principalmente nos anos iniciais da educação infantil e fundamental. Através do tato a criança começa a descobrir coisas e identificar espaços. Oferecer materiais diferentes nesses produtos para as crianças é uma forma de expandir sua capacidade de expressão e ainda de assimilação de conhecimento. Também é importante ressaltar, que ao escolher um material para jogos e brinquedos que serão utilizados por crianças, deve-se escolher uma tipologia que não possua substâncias prejudiciais a saúde e ainda que contenham características de durabilidade e de não promover algum tipo de danos físicos aos pequenos (BARATA, 2018).

Outro atributo que podemos destacar é a cor, ela também transmite sensações para os consumidores e pode fazer diferença tanto na hora da escolha do produto, dependendo da cor que lhe agrada ou até mesmo a cor que irá satisfazer melhor a sua finalidade específica. As cores quando aplicadas em produtos lúdicos/didáticos para crianças, como é o caso dos jogos e brinquedos pedagógicos, tem que projetar um imaginário infantil que conquiste as crianças, aplicando no produto um item que irá satisfazer melhor a função do objeto. Deste modo, deve-se optar por uma composição harmônica, que transmita a informação coerente, e ainda permita a criança o desenvolvimento da sua criatividade (BARATA, 2018).

Ainda de acordo com Barata (2018), nos dias atuais, o âmbito comercial possui uma quantidade muito variada de jogos e brinquedos pedagógicos direcionados ao público infantil. Deste modo, tornar-se cada vez mais indispensável, na elaboração dos produtos dentro dessa classe, estabelecer critérios que facilitem a compreensão da qualidade do jogo ou brinquedo em função da sua composição física e da adequação da forma do produto com o tipo de atividade para qual irá ser utilizado, assim como, a idade adequada da criança ao qual se destinará o produto.

Observa-se também que o conhecimento sobre espaços, está presente em diversas fases da vida da criança, desde o seu nascimento. As noções espaciais começam a ser trabalhadas desde o momento que a criança começa a de deslocar, se movimentar e isto está presente em toda a vida humana. Nesse contexto, ao conseguir trabalhar a geometria, as formas, os tamanhos, as dimensões, os materiais e as cores utilizados de maneira lúdica, consegue-se contribuir para o desenvolvimento da criança em vários tipos de atividades matemáticas, de uma forma a introduzir o conhecimento da disciplina de maneira mais dinâmica e divertida (BARATA, 2018).

Como exemplos da utilização de tipos de jogos e brinquedos, os legos, possibilitam as crianças construir casas, carros, castelos, tudo o que conseguirem imaginar. As crianças são afrontadas com problemas do cotidiano como o espaço necessário para uma construção, a altura de uma torre que pode ou não cair e até mesmo a forma correta de juntar as peças. Todas estas dificuldades levam a uma ampliação da sua capacidade de responder a problemas e da sua autonomia. Já com os blocos de construção, estas conseguem desenvolver várias capacidades, além de ser uma forma de divertimento no âmbito lúdico, este tipo de brinquedos ajudam a desenvolver capacidades matemáticas, como o 
adicionar peças ou retirar, e também é uma maneira de estimular o trabalho em equipe, o que ajuda a desenvolver capacidades de interação e sociais. (BARATA, 2018, p. 72).

Segundo Paniagua \& Palácios (2007 apud MARCATO, 2009) no período da educação infantil, as crianças conseguem ter um aprendizado a partir fundamentalmente, da ação direta sobre os objetos e de acordo com a participações em ações e situações. Deste modo, o que vale para as crianças é o contexto dos objetos, experiências, relações e atividades envolvidas com este tipo de produto. Sob este ponto de vista, podemos destacar a relação clara e evidente entre o design e a pedagogia, de modo que o design consegue auxiliar a educação, trazendo inovações e diversidade em suas ferramentas didáticas (MARCATO, 2009).

Para Marcato (2009), tanto o profissional designer quanto o educador, não devem esquecer que os jogos e brinquedos não podem perder as características que o transforma em um objeto didático. É importante projetá-lo com cautela, ressaltando sua eficiência didática e lúdica para o processo de ensino. E embora projetar seja tarefa do designer, foi encontrado na literatura sobre design de jogos e brinquedos, produtos elaborados também por profissionais da educação, porém, antes de qualquer coisa é importante ressaltar que os jogos e o brinquedos são produtos, ou seja, objetos e sendo por consequência, responsabilidade do designer. Deste modo, acredita-se que o design é um importante agente com um papel essencial para o processo de criação de materiais didáticos como os jogos e brinquedos pedagógicos.

De acordo com o que foi apresentado até o momento, pode-se observar a importância dos atributos do produto, dentro da composição física dos artefatos. Nesse caso, dos jogos e brinquedos pedagógicos, as características dos objetos se tornam um meio de comunicação dos produtos com as crianças e estes produtos têm por objetivo comunicar determinados conteúdos da matemática, no caso do objeto de estudo dessa pesquisa que objetiva compreender como as características tangíveis dos produtos se tornam um meio de comunicação que proporcionem melhor performance no que se refere à função pedagógica.

A finalidade deste trabalho, é que através dele consiga-se ter um melhor entendimento da importância do processo de Design dentro do projeto de jogos e brinquedos pedagógicos. É importante ressaltar que as características desses produtos, devem ser mediadoras de algumas atividades, como: estimular a autonomia, incentivar a curiosidade e a criatividade, favorecer a coordenação motora, estimular a lógica matemática, dentro outros. Tudo isso objetivando auxiliar o educador no seu dia-adia do processo de ensino-aprendizagem das crianças. Uma vez que, através desses produtos, os alunos e os professores consigam construir juntos vários conhecimentos matemáticos, incluindo equações básicas de soma, subtração, divisão e multiplicação; tudo isso proporcionando a divertimento e aprendizado.

Sendo assim, abriu-se um extenso espaço para discussão e reflexão acerca das relações existentes entre os jogos e brinquedos pedagógicos e o design, permitindo que as necessidades sucedidas deste processo, possa resultar em mais pesquisas na área, gerando outras possíveis discussões.

\section{Conclusão}

A utilização de jogos e brinquedos pedagógicos no ensino da matemática é comum e várias pesquisas conseguem demonstrar isso. De certo modo, os docentes estão se adaptando a esse método de ensino devido ao seu potencial didático, lúdico e eficiente para transmitir informações. Contudo, na área do Design, ainda é algo pouco estudado. Não há muitas pesquisas que investiguem a importância das propriedades físicas dos jogos e brinquedos pedagógicos. Este artigo descreveu alguns aspectos relevantes como forma de estabelecer suporte teórico para a investigação sobre o assunto, a fim de entender mais sobre a contribuição e relevância do Design de jogos e brinquedos utilizados para o ensino da matemática.

Por meio desse trabalho, foi possível verificar como os jogos e brinquedos pedagógicos influenciam o processo de ensino-aprendizagem da disciplina da matemática e como o uso dessa metodologia pode proporcionar aos alunos a oportunidade de realizar diversas atividades dinâmicas, além de vivenciar novas experiências. Além disso, foi possível observar a importância dos atributos existentes nos jogos e brinquedos pedagógicos analisando a relevância da composição física dos objetos. 
Para os estudantes, essa metodologia fornece momentos diversificados onde os mesmos conseguem ter mais contato com os demais alunos e ainda conseguem desenvolver o sentido de coletividade, já que, na maioria das vezes, essas atividades com jogos e brinquedos requerem a interação entre colegas. Sendo assim, os brinquedos e jogos pedagógicos podem funcionar como ferramenta potencializadora do processo de ensino-aprendizagem da matemática. Devido a este fato, é importante entender como esses produtos funcionam e como eles são projetados, ou seja, qual a relevância do Design dos produtos e como esta contribui para o conhecimento transmitido nas atividades de matemática.

Considerations about the Design of educational games and toys for teaching mathematics in elementary school

Abstract: This paper describes the theoretical basis of an ongoing research on the design of educational games and toys and their use as instruments that help the teaching of mathematics with the aim of making classes more dynamic, enjoyable and efficient. To this end, the study investigates the relationship between the composition of the physical attributes of educational games and toys and the teaching-learning process. The work discusses the importance of product design attributes for didactic purposes, that is, it seeks to understand how the physical elements of these products become important characteristics in the teaching process. This article presents a brief analysis on the design of educational games and toys and the relevance of using this type of resource for the teaching of mathematics, considering that it has become increasingly present in the educational field, as a way to make the classes of the discipline more attractive and motivating, enabling greater interaction, involvement and participation of students.

Keywords: Educational games and toys; Design; Teaching; Mathematics.

\section{Referências bibliográficas}

ANUÁRIO BRASILEIRO DA EDUCAÇÃO BÁSICA. São Paulo: Moderna, 2019.

BARATA, Filipa Cordeiro Lopes Fernandes. Dimensões da relação da criança com o design do brinquedo: Um estudo sobre as preferências individuais e fatores associados. 2018. $201 \mathrm{f}$. Dissertação (Mestrado) - Curso de Design, Universidade de Lisboa Faculdade de Belas-artes, Lisboa, 2018.

BESSA, Sônia; COSTA, Váldina Gonçalves da. Operação de multiplicação: possibilidades de intervenção com jogos. Revista brasileira de estudos pedagógicos, Brasília, v. 98, n. 248, p.130147, 2017.

BICALHO, Cynthia Dias; OLIVEIRA, Poliana Pereira de; AZEVEDO, Thiago Guimarães. Design e educação infantil: proposta de brinquedo educativo para crianças da pré-escola. Projética, Londrina, v. 10, n. 2, p.105-120, 2019.

BRASIL, Secretaria de Educação Fundamental. Parâmetros Curriculares Nacionais: Matemática. Brasília: MEC/SEF, 1997.

BRISCH, Mara; SEHN, Elizandra. Como conciliar jogos pedagógicos ao ensino de matemática com alunos do $3^{\circ}$ ano do ensino fundamental? Revista eletrônica científica inovação e tecnologia, Medianeira, v. 8, n. 16, 2017. E - 4875. 
CALEGARI, Eliana Paula; SILVA, Roseane Santos da. Redesenho de brinquedos: uma abordagem a partir do Design Emocional. Revista de design, tecnologia e sociedade, Brasília, v. 4, n. 1, p.121, 2017.

COELHO, Luiz Antonio L. (org). Conceitos-chave em design. Rio de Janeiro. Ed: Puc-Rio, Novas ideias. 2008.

CRUZ, Polyana Ferreira Lira da. Reflexões sobre o design na educação básica a partir da investigação da atividade de projeto como prática pedagógica: estudo de casos com professores da educação básica. 2017. 174 f. Dissertação (Mestrado) - Programa de Pós-graduação em Design, Centro de Ciências e Tecnologia, Universidade Federal de Campina Grande, Campina Grande, 2017.

A DONDIS, Donis. Sintaxe da Linguagem Visual. São Paulo: Martins Fontes, 2003. 236 p.

GODOY, C. L. S.; MENEGAZZI, M. O. Uso de jogos no ensino da matemática. Comunicação apresentada em XIV Salão Intermunicipal de pesquisa. Lutheran University of Brazil, Guaíba, 2014.

GOMES FILHO, João. Gestalt do Objeto: Sistema de Leitura Visual da Forma. 8 ed. rev. e ampl. São Paulo: Escrituras Editora, 2008.

GRANDO, Regina Célia. 0 jogo e a matemática no contexto da sala de aula. São Paulo: Paulus, 2004.

GUTHEIL, Mariane; WEBER, Cristian; PINTO, Ana. Desenvolvimento de Brinquedo/Jogo Pedagógico com ênfase na experiência de usabilidade. 50 GAMPI PLURAL, Joinville, 2015.

HESKETT, John. Design. Revisão técnica Pedro Fiori Fernandes. Tradutora Márcia Leme. São Paulo: Ática, 2008. 146 p.

LIRA, Natali Alves Barros; RUBIO, Juliana de Alcântara Silveira. A Importância do Brincar na Educação Infantil. Revista Eletrônica Saberes da Educação, São Paulo, v. 5, n. 1, 2014.

LOBACH, B. Design industrial: bases para a configuração dos produtos industriais. São Paulo: Edgard Blucher, 2001.

KISHIMOTO, Tizuco M. Jogo, brinquedo, brincadeira e a educação. $8^{\circ}$ ed. São Paulo: Cortez, 2005.

MANZINI, E. A matéria da invenção. Lisboa: Centro Português de Design, 1993.

MARCATO, Daniela de Cássia Gamonal. 0 design nos jogos geométricos aplicados ao ensino infantil. 2009. 159 f. Dissertação (Mestrado) - Curso de Design, Universidade Estadual Paulista Júlio de Mesquita Filho, Bauru, 2009.

MEFANO, Ligia. O Design de Brinquedos no Brasil: Uma arqueologia do projeto e suas origens. 2005. 143 f. Dissertação (Mestrado) - Curso de Design, Artes \& Design, PUC: Rio de Janeiro, 2005.

MOREIRA, D.; OLIVEIRA, I. 2004. 0 jogo e a matemática. Lisboa: Universidade Aberta.

OLIVEIRA, Paulo de Salles. 0 que é brinquedo. 3. ed. São Paulo: Brasiliense, 2010.

SANTANA, José Rogério; BORGES NETO, Hermínio; ROCHA, Elizabeth Matos. A sequência fedathi: uma proposta de mediação pedagógica no ensino de matemática. In: VIII ENCONTRO NACIONAL DE EDUCAÇÃO MATEMÁTICA, CONGRESSO. Recife: Sbem, p.1-11, 2004.

SEHN, Cristina Morandi. Análise da correlação entre a criatividade em atributos de forma e função com o sucesso de produtos de bens de consumo. 2014. 121 f. Dissertação (Mestrado) Curso de Design, Universidade Federal do Rio Grande do Sul, Porto Alegre, 2014.

SILVA, Lidiane de Oliveira. A função social e pedagógica do brinquedo no desenvolvimento da criança. 2015. 69 f. TCC (Graduação) - Curso de Pedagogia, Centro de Educação, Universidade Estadual do Ceará, Fortaleza, 2015.

SILVA, Renato Carneiro da. Sistema de numeração decimal: Saberes docentes e conhecimentos discentes do $3^{\circ}$ ano do ensino fundamental. 2013. 138 f. Dissertação (Mestrado) - Curso de Educação Brasileira, Universidade Federal do Ceará, Fortaleza, 2013. 
SILVEIRA, Nathalie Barros da Mota. Morfologia do objeto: Uma Abordagem da Gramática Visual/Formal Aplicada ao Design de Artefatos Materiais Tridimensionais. 2018. $171 \mathrm{f}$. Tese (Doutorado) - Curso de Design, Design, Universidade Federal de Pernambuco, Recife, 2018. 